\title{
Chyawanprash: A Nutraceutical in the Treatment of Calcium Oxalate Kidney Stones: Let Food Be Your Medicine
}

\author{
Pallavi Bhosle $^{1}$, Kaushal Gorle ${ }^{1}$, Arundhati Deokar ${ }^{1}$ \\ ${ }^{1}$ Shreeyash Institute of Pharmaceutical Education and Research, Aurangabad \\ Corresponding Author: Pallavi Bhosle
}

\begin{abstract}
Nephrolithiasis is a process of forming renal calculi or stones in the kidneys. Certain biochemical changes such as formation of reactive oxygen species are the potential causes for epithelial tissue damage resulting in the idiopathic formation and accumulation of calcium oxalate crystals. There are many evidences available for the protective involvement of antioxidants against oxidative stress in nephrolithiasis. Also many formulations of traditional plants having stone breaking, stone dissolving, and diuretic activities, are available in market as ayurvedic treatments for nephrolithiasis. Most of the ayurvedic formulations available in the treatment of nephrolithiasis are generally churna, syrups, tablets or capsules. Many patients show incompliance for regularly ingesting these formulations. Chyawanprash is one of the oldest and most popular Ayurvedic preparations; it is widely sold and consumed as a dietary supplement as well as health promotive and disease preventive formulation. Considering these factors the Chyawanprash formulation was made using all these traditional plants having well reported antinephrolithiatic, nephroprotective and diuretic activities to treat nephrolithiasis in effective and compliable manner. Chyawanprash is prepared as per the instructions documented in Ayurvedic texts Charaka Samhita, the ancient Ayurvedic treatise. Its evaluation is done to calculate its organoleptic properties, $\mathrm{pH}$, shelf life, stability and microbial contamination, Phase separation. Hence we can conclude that Chyawanprash will no longer be just an Immunity builder but it can be used as an effective and compliable medicine for nephrolithiasis treatment.
\end{abstract}

Key Words: Chyawanprash, Traditional medicine, Nutraceutical formulations, Nephrolithiasis, Kidney stones, Calcium oxalate crystals.

\section{INTRODUCTION}

In 1950's chyawanprash entered the consumer market and stepped as an overthe-counter product. Chyawanprash is a formulation of Ayurvedic rich herbs and minerals. The blend of which explores the strength and stamina of human body. Chyawanprash is the mixture simple decoction of herbs, extracts of herbs followed by honey or jaggery and some spices. ${ }^{[1]}$ It is Immunity Enhancer and has been used since ancient period for strength, stamina and endurance; it is also a vital anti aging formulation. Amla (Phyllanthrus emblica), the richest source of Vitamin $\mathrm{C}$ and a Homeostasis sustainer are used as a base in the formulation of chyawanprash. ${ }^{[2]}$ On regular consumption ofit is beneficial in maintenance of body function and having health beneficiary, preventive and curative role in health. ${ }^{[1,2]}$ Kidney stone or Nephrolithiasis is a most common and ancient condition in which calculi(stones) form within the tubular lumen and renal pelvis of individual. In India, Kidney stone is prevalent, with an expectancy of $12 \%$ in a total population reported to be prone to urinary stones. ${ }^{[3]}$ Calcium Oxalate, Calcium Phosphate, Uric acid are predominant components of kidney stone. Recurrence is 
usual after a first stone. In absence of preventive or curative treatment; the Probability of recurrence for idiopathic calcium stones after the initial event is 40 $50 \%$ at 5 years and $50-60 \%$ by 10 years. ${ }^{[4]}$ So the consistent treatment regime is important in its management. Varun moola (Crataeva Nurvala)and Palsahpushpa (Butea monosperma) are useful in complaints of urinary systems such as kidney stones and also has analgesics, lithotryptic and anti-inflammatory action. ${ }^{[5]}$ Citrus medica (Citron fruit) istraditionally considered effective in prevention of crystal aggregation and also has diuretic and antioxidant activity. Ashwagandha is an immunity booster and a free radical scavenger. Pomegranate juice contains relevant amounts of active biological compounds which reduce the harmful effects of chronic heavy metal exposure.

${ }^{[7]}$ Horse gram extract is highly effective in the dissolution of calcium oxalate crystals and decrease their particle size considerably. [7] Hydro alcoholic extract of Gokhru (Tribulus terrestris) and Guggul (Commiphora wightii) has antiinflammatory, antihypertensive, diuretic, and urinary anti-infective properties. Basil leaves (Ocimum basilicum) are Nephroprotective agents are material that has potential to minimize the effects of nephrotoxic agents. [9] Black pepper, nutmeg, cinnamon and Ginger has chelating capacities, and radical-scavenging properties. ${ }^{[6,7]}$

The present study, A chyawanprash formulation was prepared and its evaluation was done on the basis of organoleptic, phase separation, microbial contamination explore the Nephrolithic or Urolithiatic, Neuroprotective and Diuretic Potential of components used in Chyawanprash, which also comes under Nutraceuticals.

\section{MATERIALS AND METHODS}

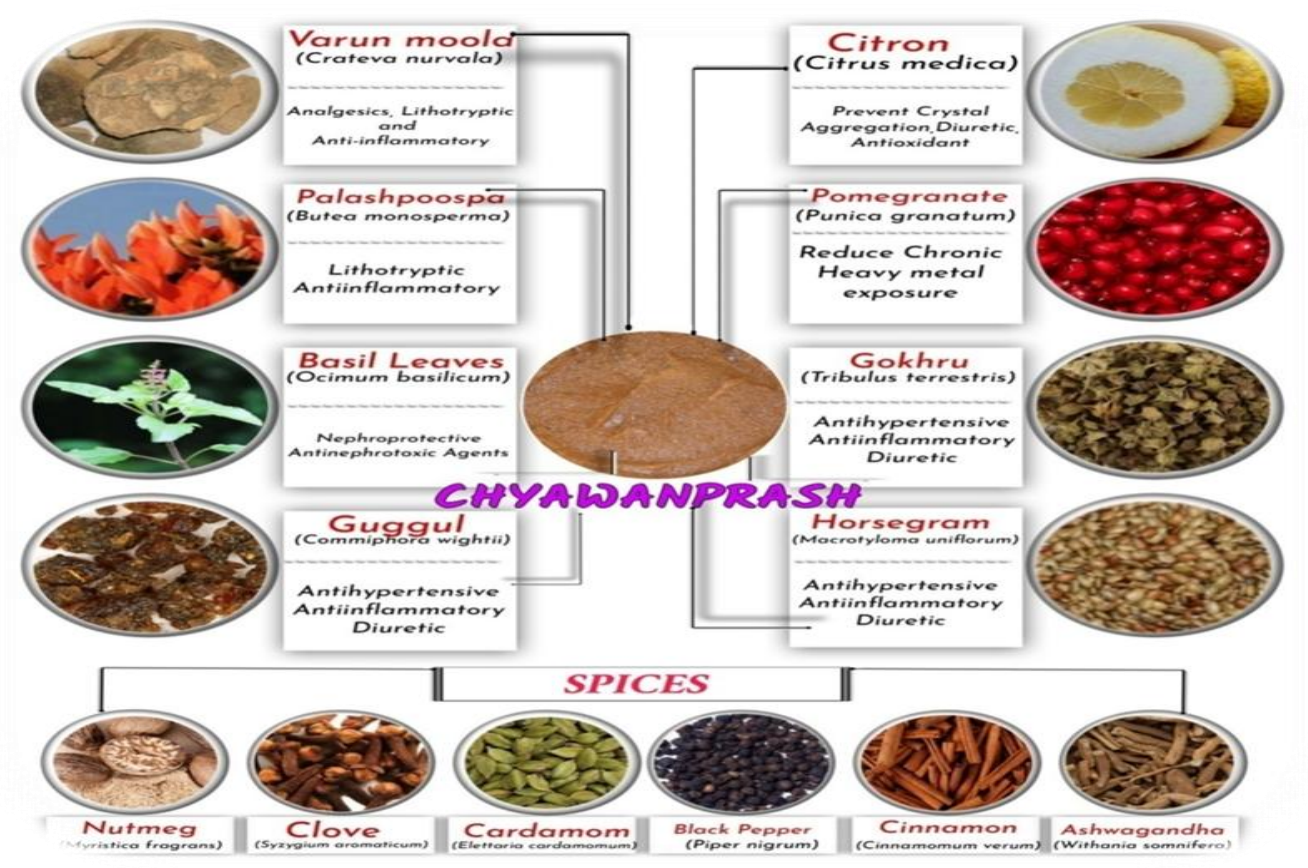

Fig01: Material used in the formulation of Chyavanprash with their specified uses

Fruits of Amla, Varun moola (Crataeva Nurvala roots) and Palsahpushpa (Butea monosperma flower), Gallimbu (Citrus medica fruit), Ashwagandha (Withania somnifera bark), powder, Pomegranate juice, Horse gram extract,
Basil leaves(Ocimum basilicam), Gokharu powder (Tribulus terrestris), Guggul (Commiphora wightii), jaggary, and spices like cardamom, clove, cinnamon, Black pepper etc were obtained from the local market, Aurangabad, Maharashtra, India. 
The plants were identified and authenticated by Dr. G.G Tapadiya, Department of Pharmacognosy, Shreeyash Institute of Pharmaceutical Education And Research, Aurangabad.

Authoritative texts were searched for recipes, processes, and other technical details of Chyawanprash. Labels of marketing of Chyawanprash products (Indian) were studied for the health claims.

\section{Method of Preparation:}

The method of preparation was referred from the Ayurvedic Pharmacopoeia of India. ${ }^{[8]}$ All the ingredients of pharmacopoeial quality were taken. These ingredients of the formulation composition were properly Washed, dried, and powdered. A sufficient amount of water was added to the Kvatha Dravya. Fresh fruits of Amla/Gooseberries were taken; they were washed and tied into a bundle using muslin cloth. The bundle was immersed into the vessel, heated well. It was then removed from the vessel when Amla/Gooseberries become soft. Continued to boiling till water reduces to one fourth and filter the decoction through a muslin cloth. The filtrate was kept safe for use in the formulation by removing the fibers and seeds by rubbing through a piece of cloth which is called as Amalaki pisti as per ayurvedic terms. Pisti was fried with the Ghee (Ghrta) and mixed in equal proportions. Properly fried Pisti would release the Ghrta. Then Sarkara to be added to the filtered Kvatha, also fried Pisti added and boiled to Leha Paka. Final stage of Leha Paka was then assessed by putting 2 to $3 \mathrm{~g}$ in a glass of water at room temperature. It was allowed settle down in the water and did disperse at least for 5 to $10 \mathrm{~min}$. Then the vessel from fire was removed and allowed to cool at $500^{\circ} \mathrm{CAddedPraksepa}$ Dravya and mixed thoroughly to prepare a homogeneous blend. On cooling at room temperature; It was then Packed in tightly closed containers to protect from light and moisture shown in the photograph below. ${ }^{[8]}$

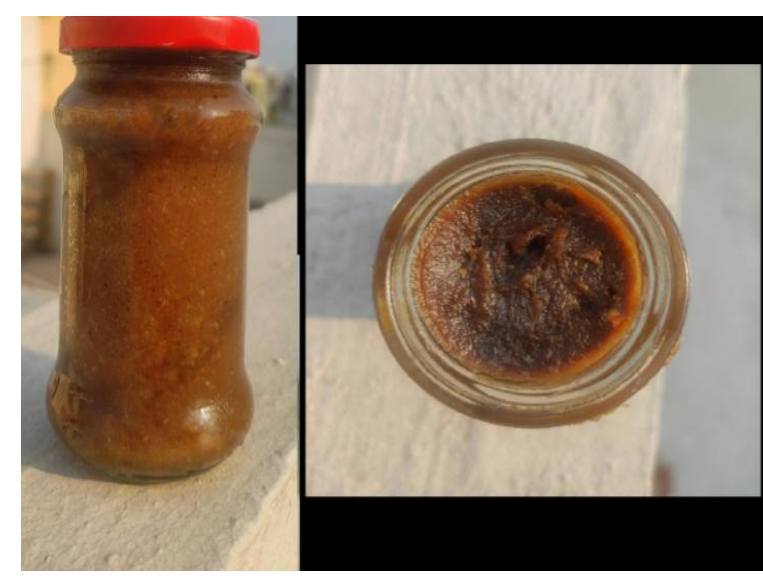

\section{Mode of Administration}

Chyawanprash can be used by all age groups in patients suffering from nephrolithiasis/ Urolithiasis. Chyawanprash should be taken in a quantity such that it does not interfere with hunger and appetite for food. The general dosage of Chyawanprash (12-28 g) is to be taken with or without milk (100-250 ml) on an empty stomach in the morning. ${ }^{[6]}$

\section{Evaluation of Chyawanprash}

The Chyawanprash Nutraceutical formulation was evaluated for the physiochemical parameters, organoleptic properties, microbial growth, and storage conditions evaluation.

The Ayurvedic Pharmacopoeia of India (API) has published a monograph on Chyawanprash along with a brief method of preparation and various physicochemical and assay tests as official quality standards. These include description, identification, $\mathrm{pH}$, and microbial examination. ${ }^{[8]}$

\section{Organoleptic Properties}

Based on the available market samples, it was found that the consistency flavor and taste of Chyawanprash vary from company to company. Here we have compared our Chyawanprash with one that is marketed as Dabur Chyawanprash. The oraganoleptic properties were compared and noted in the results.

Initial stability study of formulation (Storage conditions): 
The Chyawanprash formulation was packed in Glass, plastic bottles, jars and 400 gauge polyethylene bags and stored at ambient temperature to study their storage condition by observing changes in moisture and microbial load. The formulation was drawn from each packaging material and analyzed for their quality for a period of 90 days at one month interval.

Moreover, the specimens were kept at various storage conditions like Natural sunlight $\left(40^{\circ} \mathrm{C} \pm 2^{\circ} \mathrm{C}\right)$, room temperature $\left(\left(28 \pm 05^{\circ} \mathrm{C}\right)\right.$ and in refrigerator $\left(5 \pm 3^{0} \mathrm{c}\right)$ to observe the effect of temperature on storage behavior. The formulation was kept in these conditions for 90 days at one month interval and analyzed for the variations in organoleptic properties, moisture and microbial load.

\section{Microbial Assessment:}

Microbiological examination Microbiological examination of the preparation was carried out by the method prescribed by Istavankiss (1984). The method for the microbial assessment as per ayurvedic Pharmacopoeia is not valid for the preparation as it involves the component that inhibits the multiplication under the test conditions of micro-organisms that can be present. Hence, the preparation was analyzed for the microbial assessment by simple streaking plate method.

4. Physicochemical Properties: The physiochemical parameters like a loss on drying (LOD) at $105^{\circ} \mathrm{C}$ and moisture content were determined. LOD determination is very important parameter as any excess of water in plant materials will promote bacterial growth, the presence of moulds and may cause deterioration by hydrolytic activity.

\section{Toxicity and Safety Concerns:}

The information available in vitro and in vivo studies are still limited about Chyavanprash formulation. Moreover, there is no evident information on toxicity has been available until now. A wide scope is open for future researchers to reach better conclusions for the use of this formulation in various diseased conditions.

\section{RESULTS}

Organoleptic Properties: The chyawanprash formulation was found to possess almost similar characteristics when our Antinephrolithiatic Chyawanprash formulation was compared to the standard product. The results were reported in the following table no 1.

Table No 1: Comparative evaluation of Oraganoleptic characterstics of Antinephrolithiatic Chyawanprash formulation and standard marketed chyavanprash formulation

\begin{tabular}{|l|l|l|}
\hline Parameter & Standard product (Dabur Chyawanprash) & Antinephrolithiatic Chyawanprash formulation \\
\hline Color & brownish black appearance & dark brown appearance \\
\hline Odour/Flavor & spicy flavor & Mixed flavor of condiments and basil leaves \\
\hline Taste & astringent feel after taste with aroma of condiments & a sweet, sour and spicy taste with aroma of condiments \\
\hline Consistency & Thick consistency & Fruit- Jam like Thick consistency \\
\hline
\end{tabular}

\section{Storage studies:}

Table No 2: Storage conditions for the Antinephrolithiatic chyawanprash formulation

\begin{tabular}{|c|c|c|c|}
\hline GLASS JAR & Natural sunlight $\left(40^{\circ} \mathrm{C} \pm 2^{\circ} \mathrm{C}\right)$ & Room temperature $\left(\left(28 \pm 05^{0} \mathrm{C}\right)\right.$ & Refrigerator $\left(5 \pm 3^{0} \mathrm{c}\right)$ \\
\hline Moisture content & Decreased & Remains Constant & Slightly Decreased \\
\hline Microbial load & Found & Not found & Not found \\
\hline Organoleptic properties & Brownish black colour & No change in colour & No change in colour \\
\hline Stability & Not Stable & Stable & Stable \\
\hline $\mathrm{pH}$ & 4 & 4 & 4 \\
\hline
\end{tabular}

\begin{tabular}{|c|c|c|c|}
\hline PLASTIC BOTTLE & Natural sunlight $\left(40^{\circ} \mathrm{C} \pm 2^{\circ} \mathrm{C}\right)$ & Room temperature $\left(\left(28 \pm 05^{0} \mathrm{C}\right)\right.$ & Refrigerator $\left(5 \pm 3^{0} \mathrm{c}\right)$ \\
\hline Moisture content & Slightly Decreased & Remains Constant & Slightly Decreased \\
\hline Microbial load & Found & Not found & Not found \\
\hline Organoleptic properties & No change in colour & No change in colour & No change in colour \\
\hline Stability & Not Stable & Stable & Stable \\
\hline $\mathrm{pH}$ & 4 & 4 & 4 \\
\hline
\end{tabular}


For selecting appropriate storage container as well as stability and phase separation analysis; this study was carried out. Both Glass jar and Plastic bottle showed similar results in given aspects, hence both packaging materials can be used. But it is advised to prevent it from sunlight. The results were reported in Table no 2.

3. Microbial Assessment: Microbial growth is one of the important concerns for any formulation. Hence the evaluation of any microbial growth for moulds, fungus, bacteria was checked after 7 days and 90 days of chyavanprash formulation. The results were satisfactory and there was no growth found on it; expressed in the table no 3.

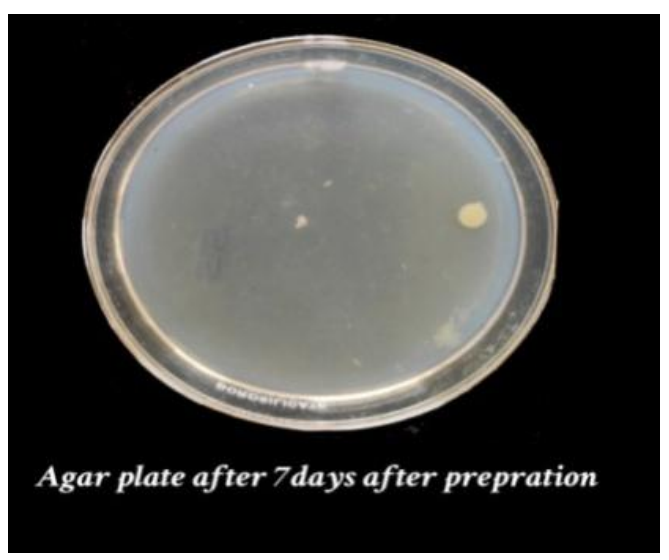

Table no3: Evaluation of microbial load for 7 and 90 days after preparation

\begin{tabular}{|l|l|l|}
\hline 7 days & Bacteria & Negative \\
\hline 7 days & Fungi & Negative \\
\hline 7 days & Yeast & Negative \\
\hline \multicolumn{3}{|l|}{} \\
\hline 90 days & Bacteria & Negative \\
\hline 90 days & Fungi & Negative \\
\hline 90 days & Yeast & Negative \\
\hline
\end{tabular}

\section{Physico-chemical parameters:}

As per the Ayurvedic Pharmacopoeia of India the preparation has passed the Physico-chemical parameters. As Loss on drying was noted $7 \%, \mathrm{pH}(1 \%$ aqueous solution) 4 and moisture content was noted

\section{DISCUSSION}

Natural health products with medicinal value are gaining importance in clinical research as they offer better alternatives, owing to fewer side-effects and cost-effectiveness than conventional synthetic nutraceuticals.

Currently, Chyawanprash has acquired a large accepted user base in India and in a few countries out-side India. The documented clinical studies from electronic databases and Ayurvedic books evidenced that individuals who consume CHYAVANPRASH regularly for a definite period of time showed improvement in overall health status and immunity. However, scientific exploration of Chyawanprash in nephrolithiasis is still to be warranted to understand its therapeutic efficacy. While assembling the scattered information about the therapeutic potential of Chyawanprash it was noticed that; it is available only as immunity, strength, and stamina and vitality booster. And there is a need to explore the therapeutic potential of Chyawanprash in various disease conditions of liver, Kidneys etc by using certain traditional medicines. Thus, an effort was made to compile the procedure from ancient Ayurvedic texts and treatises to formulate the Chyawanprash, along with ethnobotanical, ethnopharmacological, and scientifically validated literature about uses of above traditional plants in various kidney diseases. And the formulation was prepared, that highlights the role of Chyawanprash in the therapy of nephrolithiasis.

\section{CONCLUSION}

Commercialization of this traditional formulation of Chyawanprash in nephrolithiasis, is still to be explored and accepted. It can be used widely as a health supplement and a treatment measure among patients of nephrolithiasis or urolithiasis. It should be advised and used by all age groups having ill kidney conditions such as nephrolithiasis or urolithiasis.

\section{Acknowledgement: None}

Conflict of Interest: None

Source of Funding: None 
Pallavi Bhosle et.al. Chyawanprash: a nutraceutical in the treatment of calcium oxalate kidney stones: let food be your medicine.

\section{REFERENCES}

1. Rohit Sharma, Natália Martins, Kamil Kuca, _Ashun Chaudhary, Chyawanprash: A Traditional Indian Bioactive Health Supplement, Biomolecules 2019, 9, 161

2. Parle, M.; Bansal, N. Traditional medicinal formulation, Chyawanprash-A review. Ind. J. Tradit. Knowl. 2006, 5, 484-488

3. Sofia N.H., Manickavasakam K., Walter T.M. Prevalence and risk factors of kidney stone. GJRA. 2016; 5:183-187

4. Gillen DL, Coe FL, Worcester EM. Nephrolithiasis and increased blood pressure among females with high body mass index. Am J Kidney Dis. 2005; 46(2):263-269.

5. Mohod Poonam, Mohod Sharad, Anuradha Thapa, Far-fetched properties of varun moola (crataeva nurvala roots) \& palashpushpa (butea monosperma flowers) to manage urolithias, international journal of ayurveda and Pharma Research,February 2016, Vol 4,Issue 2, 57-61

6. NC Shah. The History of Botanicals of "Ashtawarga": The Most important Ingredients Used in "Chyawanprash" and the Famous Rejuvenating Tonic of Ayurveda. Journal of Natural \& Ayurvedic Medicine. 2019; 3.
7. Dr. Gowrimeenal, A., Dr. Banumathi, P., Dr. Premalatha, M. R., Dr. Rajesh, R. and Dr. Arulmozhiselvan, K., Formulation and Evaluation of nutraceutical mix, International Journal of Information Research and Review Vol. 05, Issue, 01, pp.5132-5136, January, 2018

8. The Ayurvedic Pharmacopoeia of India, Chyavanprasa, Vol-I, First Edition;AFI, Part-1,2003,3:11

9. Khurana, S., Tiwari, R., Sharun, K., Yatoo;, M., Gugjoo, M. and Dhama, K., Emblica officinalis (Amla) with a Particular Focus on Its Antimicrobial Potentials: A Review. Journal of Pure and Applied Microbiology, 201913(4), pp.1995-2012.

10. Bijarnia RK, Kaur T, Singla SK and Tandon C: A novel calcium oxalate crystal growth inhibitory protein from the seeds of Dolichos biflorus (L.). The Protein Journal 2009; 28(3-4): 161-8.

How to cite this article: Bhosle P, Gorle K, Deokar A. Chyawanprash: a nutraceutical in the treatment of calcium oxalate kidney stones: let food be your medicine. Int J Health Sci Res. 2021; 11(7):303-308. DOI: https://doi.org/10. 52403/ijhsr.20210741 